\title{
A short history of geophysical radar at Arecibo Observatory
}

\author{
J. D. Mathews \\ The Pennsylvania State University, Radar Space Sciences Lab, 323A EE East Univ. Park, PA 16802-2707, USA \\ Correspondence to: J. D. Mathews (jdmathews@psu.edu)
}

Received: 21 November 2012 - Revised: 15 February 2013 - Accepted: 20 February 2013 - Published: 13 March 2013

\begin{abstract}
As Arecibo Observatory (AO) approaches its 50th anniversary, it is appropriate to review the many radars and ionospheric heaters that have been deployed on or near the $305 \mathrm{~m}$ dish and to summarize some of the innovative radar-based geophysical research that has resulted. The reasons William E. (Bill) Gordon developed the $305 \mathrm{~m}$ Arecibo dish are well known but are briefly reviewed. The early and then more recent radar/feed designs are reviewed as geophysical uses of Arecibo have evolved and as the full potential of the dish and nearby facilities was and is being realized from HF through S-band frequencies. This history surely has some gaps and there are a few mysteries. The community is encouraged to fill these gaps and to help complete the history.
\end{abstract}

\section{Introduction}

The initial manifestation of Arecibo Ionospheric Observatory (AIO) was built over the period from June 1960 through August 1963 via US Department of Defense ARPA (Advanced Research Projects Agency) funding under the initiative of, and design specifications developed by, William E. Gordon and his colleagues Henry Booker and Ben Nichols (Gordon et al., 1958; Altschuler, 2002). A series of construction photos for this period are available at the AO website (http: //www.naic.edu/history_gal/historicgal.html). Professor Gordon was then a faculty member in the Cornell University School of Electrical Engineering. A short but compelling biography of Dr. Gordon as of 1966 is given by Clarey (1966). Cornell managed AIO - first for the Air Force and then, beginning in 1969, for NSF (National Science Foundation) from its inception through 30 September 2011, after which new management under the lead of SRI International began operations. AIO was primarily intended for incoherent scatter radar studies of the earth's ionosphere. However, as recounted by Gordon, Cornell Astronomy Professor Thomas "Tommy" Gold realized that the new AIO system could also function as the most sensitive instrument for the also relatively new fields of radio and radar astronomy (Butrica, 1994). Today Arecibo Observatory is used for atmospheric and ionospheric studies, planetary radar astronomy, and radio astronomy. It remains the most sensitive such facility and has been or is being used over a frequency range from about $3 \mathrm{MHz}$ (on-dish high frequency (HF) heating; Sulzer et al., 1982) through about $10 \mathrm{GHz}$ (radio astronomy).

The significant role of AO in planetary radar is nicely recounted in Buderi (1996) and in Butrica (1996). Gordon (1958b) notes that the parabolic-dish version of what would become Arecibo Ionospheric Observatory would enable radio astronomy observations and be suitable for planetary radar. Here we concentrate on the various geophysical radars - and the science thereby enabled - that have been placed on or adjacent to the $305 \mathrm{~m}$ dish.

\section{In the beginning}

The story of the path William E. Gordon traversed on the way to the 1 November 1963 dedication of Arecibo Ionospheric Observatory is well recounted by Butrica (1994), Robinson et al. (2009), Cohen (2009), Appendix A of Subcommittee (2008), and others. However highlights include his having conceived the concept of incoherent scattering and ultimately of the Arecibo $305 \mathrm{~m}$ dish in the spring of 1958. The rapid evolution of Gordon's idea of incoherent scattering from free electrons in the earth's ionosphere is reflected in the 29 May 
1958 Cornell School of Engineering seminar announcement reproduced as Figure 6 in Cohen (2009). Cohen also reports an April 1958 presentation to the Cornell ionosphere group on these earliest ideas. The idea progressed rapidly with his submission of the first paper on the subject to the Institute of Radio Engineers (IRE). This was received on 11 June 1958 and published in November 1958 (Gordon, 1958b).

While Gordon was refining the Arecibo designs, he was famously in contact with Dr. Kenneth Bowles, a recent Cornell $\mathrm{PhD}$, then at the National Bureau of Standards (NBS) in Boulder, Colorado. Bowles had access to an NBS $41 \mathrm{MHz}$ forward-scatter transmitter/antenna system located near Long Branch (Havana) Illinois. All he needed was a suitable zenith-looking antenna system of sufficient gain and capability to handle the 4-6 MW peak power. The $116 \mathrm{~m} \times 140 \mathrm{~m}$ half-wave dipole array (1024 elements) was quickly built by a tree surgeon from Ithaca, New York and the experiment to test for incoherent scattering was conducted with positive results (Bowles, 1958). On 22 October 1958 Gordon, then chairman of the US National Committee URSI (International Union of Radio Science) and attending the URSI/IRE (Institute of Radio Engineers) Joint Meeting at Penn State University, gave the fourth paper of the 14:0017:00 EST session 3 on "Scattered Signals" titled "Incoherent Scattering of Radio Waves by Free Electrons with Applications to Space Exploration by Radar" (Gordon, 1958a). This talk featured the announcement that Ken Bowles had earlier that day observed incoherent scattering from the ionosphere (Butrica, 1994). Bowles' paper on this result was received at Physical Review Letters on 12 November 1958 and published in the 15 December 1958 edition (Bowles, 1958). A copy of the relevant pages of the URSI abstract booklet (discovered in the National Academy of Sciences archives) will be made available online.

Even before submission of the IRE paper, Gordon's work on antenna design was proceeding under some existing ONR (Office of Naval Research) funding that he had under the direction of Dr. Arnold Shostak at ONR (Butrica, 1994). Some time between the submission of the IRE paper and its publication in November 1958, a preliminary design for a 1000foot diameter parabolic dish to be located in a sinkhole (it is unclear when the actual sinkhole was selected) near Arecibo, Puerto Rico was produced as seen in Fig. 1. However, after having searched for additional funding sources, the newly created ARPA (Advanced Research Projects Agency) and the primary ARPA contact, Ward Low, provided the necessary continuing funding. Additionally, with critical insight aimed towards flexibility of the AIO reflector, Ward Low asked Gordon to visit the antenna group at the Air Force Cambridge Research Laboratories (AFCRL) to talk about spherical reflectors. Spherical reflectors allow beam steering at the cost of using line feeds to correct the incumbent spherical aberration. This led to the adoption of a much more flexibility system with a $305-\mathrm{m}\left(70^{\circ}\right)$ spherical cap reflector, the threetower azimuth-elevation tracking platform, and use of line-

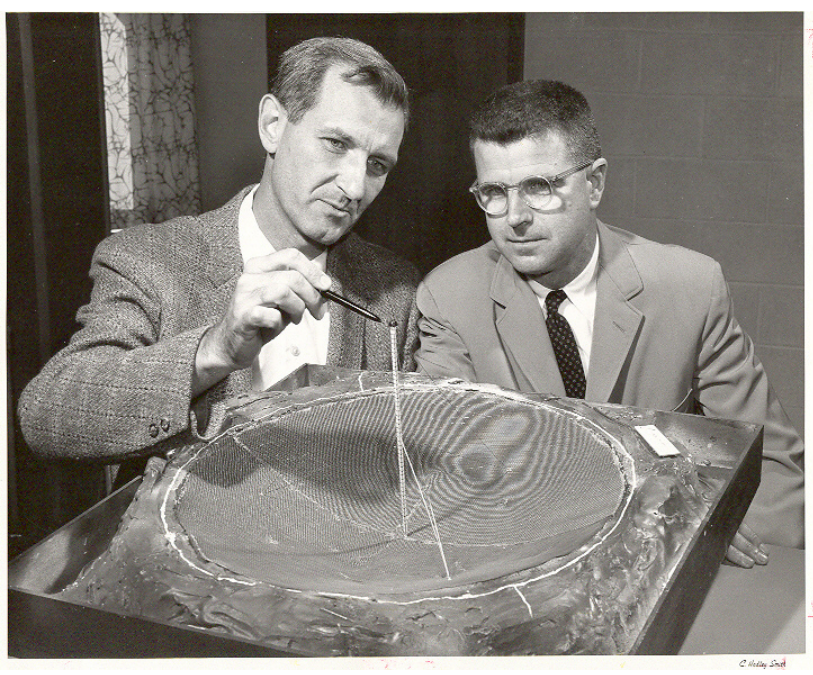

Figure 1. William E. Gordon and William McGuire working with a late 1958 model of the Arecibo radar dish and feed system. Note that the original feed system envisioned was simply a 500foot tower at the center of the parabolic dish. Professor McGuire was on the faculty of the Cornell Department of Civil Engineering and was involved in the structural design and in the maintenance of the Arecibo dish and platform structural infrastructure for many decades. (Photo courtesy of Cornell University and Prof. D. B. Campbell; also Robinson et al., 2009.)

feeds. ARPA received the construction proposal in the summer of 1958 with a funding contract signed with AFCRL in November 1959 (Altschuler, 2002). An early description of the design and construction process is given by Berth (1966). The first (less than successful) $430 \mathrm{MHz}$ linefeed used at AIO is shown in Fig. 2. Linefeeds at $430 \mathrm{MHz}$ and the BMEWSderived radar system will be discussed in a later section. Section 5 of Cohen (2009) gives a very thorough description of the inception through dedication phase of AIO.

The first Arecibo Advisory Committee was formed to advise ARPA and AFOSR on the scientific issues related to AIO (Gordon, 1962b). Ronald Bracewell chaired the committee with Herbert Friedman, Fred Haddock, Colin Hines, Otto Struve, and Arthur Waynick as members. This committee first met at AIO on 27-28 November 1962.

Figure 3 shows the Arecibo Ionospheric Observatory (AIO) as it looked as construction was completed and as the facility was dedicated on 1 November 1963. The dedication and brief history of AIO was reported in Physics Today (Editor, 1964). AIO was at this point managed and operated by Cornell University under an Air Force contract and directed by Gordon. AIO was, however, a multi-use facility with interests in radio astronomy and planetary radar as well as ionospheric studies. This may have led to the ascendency of Cornell astronomy influences on Arecibo and perhaps to the eventual move of Gordon to Rice University, where he would remain for the remainder of his career (Butrica, 


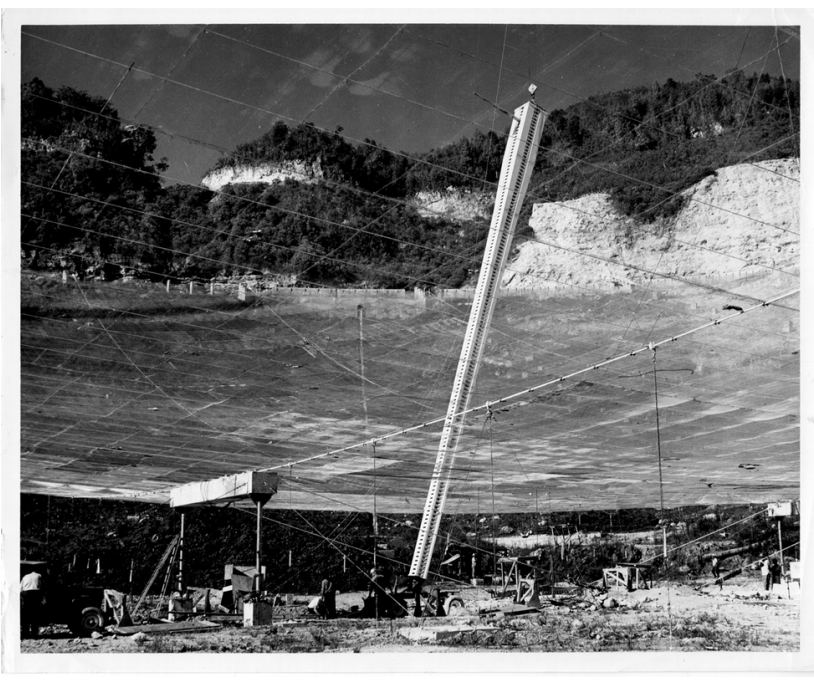

Figure 2. The original $430 \mathrm{MHz}$ square cross-section linefeed as it was raised to the carriage house in this photo dated 14 August 1963. Photo courtesy of Cornell University and Arecibo Observatory.

1994). Gordon (1964) gives a delightful early history of AIO that emphasizes the versatility and potential of the facility and thoroughly supports the radio astronomy and planetary radar astronomy initiatives. These early thoughts are amplified in his oral history interview (Butrica, 1994). Details of the evolving science and of the individuals, institutions, funding sources, and politics behind Arecibo are given in Chapter 4 of Butrica (1996). Cohen (2009) thoroughly reviews the early history of Arecibo and the context that led to rapid construction of the facility. Rankin (2008) gives some details on life in Puerto Rico in the late 1960s along with a description of the computing environment at AIO and compelling details on the excitement surrounding early pulsar work.

The National Science Foundation took over funding and management oversight of AIO on 1 October 1969. AIO became Arecibo Observatory of the National Astronomy and Ionosphere Center (NAIC) that was also based at Cornell (Altschuler, 2002). The first major upgrade that included a new dish surface was dedicated on 15-16 November 1974. The state of the observatory systems at that point is described by LaLonde (1974). The second major upgrade, which included the Gregorian dome that replaced carriage house \#2, was dedicated on 14 June 1997. This upgrade included a second $430 \mathrm{MHz}$ feed allowing dual-beam incoherent scatter observations.

\section{The AlO $430 \mathrm{MHz}$ radar}

As Gordon investigated the state of radar technology in 1958 relative to the needs for detection of incoherent scattering from the upper ionosphere (Gordon, 1958b), he was aware via MIT Lincoln Laboratories, AFCRL, and other sources of the BMEWS (Ballistic Missile Early Warning System) radars. As described in Chapter 19 of Buderi (1996) the designers of the BMEWS radar systems faced the same challenges as Gordon. They needed what we now refer to as HPLA (high-power, large-aperture) radars. Fortunately, Lincoln Labs was at the forefront of this development (Delaney and Ward, 2000) and Gordon was certainly fully aware of this. In particular, various high-power klystrons were being developed with these systems ultimately fielded at both Millstone (location of the MIT Lincoln Labs test radars and now home to the MIT Haystack Observatory (http://www. haystack.mit.edu/atm/mho/about/index.html) and Arecibo. Early high-power UHF klystrons were built by Eimac Corporation (ultimately a division of Varian Associates; http: //www.cpii.com/history.cfm) and then by Varian and finally by Litton (see page 14 of Caryotakis, 2005; also pages 409410 of Buderi, 1996), who ultimately provided the tubes for the AIO transmitter. The original AIO $430 \mathrm{MHz}$ transmitter system (still in use but with substantial updates) was designed and built for AIO by Levinthal Electronic Products (later Radiation at Stanford) where the project engineer was Gene E. Talmadge. The AIO/AO transmitter (Radiation at Stanford Model PC-349) is very similar to the Millstone (Haystack) $440 \mathrm{MHz}$ systems but operates at $430 \mathrm{MHz}$ and originally used a pair of (production BMEWS) Varian VA843 klystrons (J. B. Hagen, personal communication, 2013) that were not too successful, resulting in a move to "socketcompatible" Litton L-3403 tubes that exhibited reasonable lifetimes but an efficiency of under $30 \%$. Finally, more modern and more efficient Litton L-5773 klystrons were adopted and are in use today. All these klystrons were designed for a nominal $1 \mathrm{MHz}$ bandwidth and, as pairs, to deliver a nominal peak power of $2.5 \mathrm{MW}$ ( $6 \%$ duty cycle). The AIO transmitter fed the CH\#1 linefeed via 1500 feet of WR2100 waveguide that connected to the carriage house ( $\mathrm{CH \# 1}$ ) via a slotted probe and then to the linefeed via a turnstile junction (Hagen, 2005). This basic system remains in place today.

The transmitter system arrived at AIO well before the dish and platform were completed. As the radar was available, a 16-foot-per-side, square-aperture $430 \mathrm{MHz}$ horn antenna that towered some 60 feet was built, under the direction of Bell Labs engineer, T. E. Talpey (then on leave from Bell Labs and employed by Cornell), and L. M. LaLonde and used to test the entire $430 \mathrm{MHz}$ transmitter and receiver system including the turnstile junction (Gordon, 1962a). This system (shown in Fig. 4) was confirmed as having a $\sim 10^{\circ}$ half-power beamwidth and was in operation by mid-October 1962. It was used to receive the sun in transit and to obtain lunar echoes as the moon transited near zenith. The lunar echoes were additionally received bistatically from near Ithaca using a $17-\mathrm{ft}$ dish. This system was also used to detect the Echo I satellite and to search, apparently with no success, for incoherent scattering.

As AIO observations commenced using the on-dish $430 \mathrm{MHz}$ radar, incoherent scattering was readily detected. However, it was immediately clear that the original square 


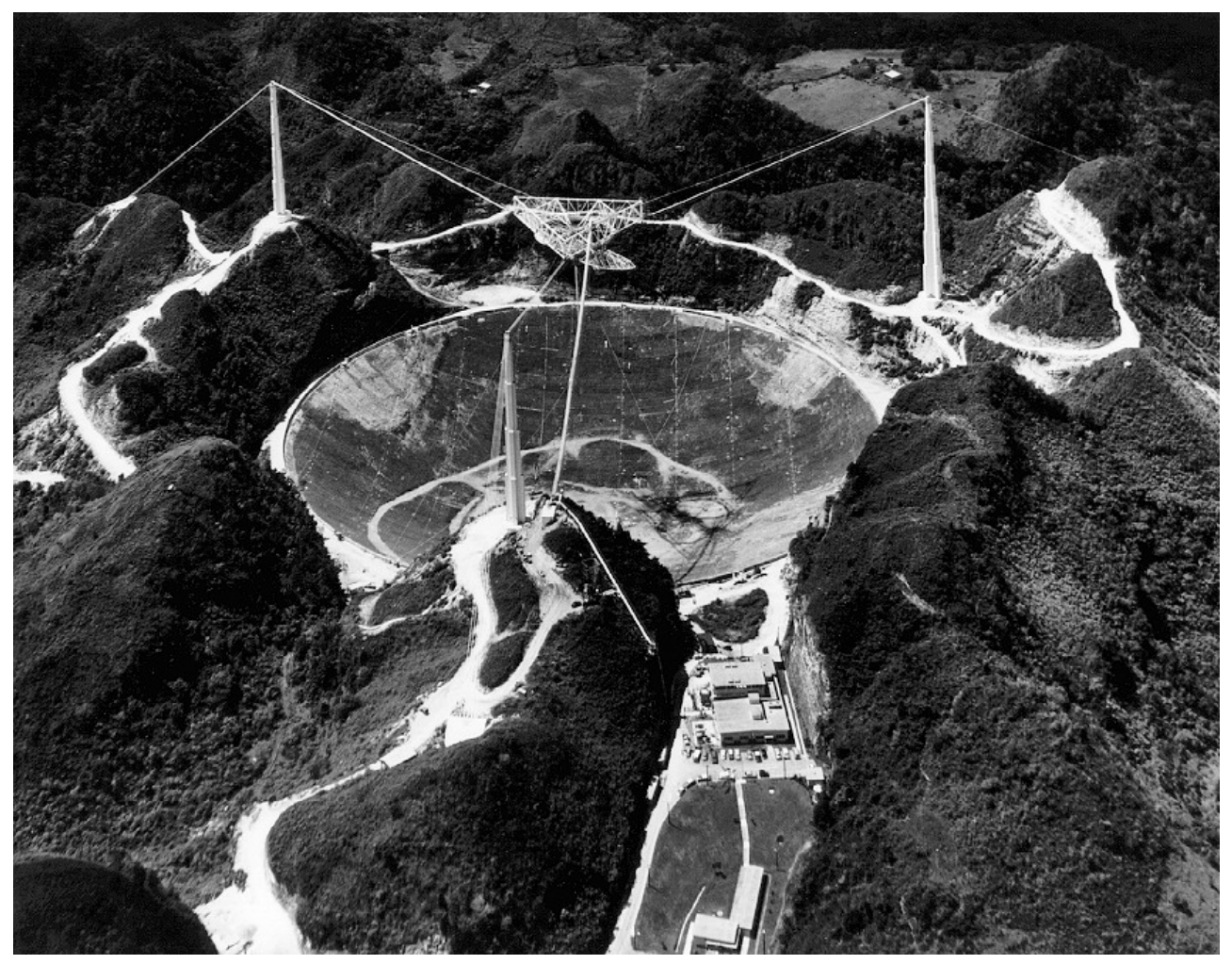

Figure 3. AIO at about the time it was dedicated on 1 November 1963. Note the $430 \mathrm{MHz}$ linefeed projecting below the elevation arm - see Fig. 5 for a close-up picture of this linefeed. The waveguide from the transmitter located in the left side of the building nearest the dish is mounted above the catwalk that reaches from the triangle to near the base of the tower nearest the buildings and is then seen to reach from this point to the top of the cliff above the transmitter/operations building. Photo courtesy of Cornell University and Arecibo Observatory.

cross-section linefeed (Fig. 2) had a gain of only $\sim 56 \mathrm{dBi}$ and an aperture efficiency of only $22 \%$ (LaLonde, 1974). These values were well below the theoretical expectations for this system and would lead to the replacement of this linefeed. The contract under which this linefeed was designed and built is apparently described in Kay (1961) which the author has been unable to locate but which is referenced in LaLonde and Harris (1970).

The earliest publication using the incoherent scatter radar at AIO appears to have been Thome (1964), who in the acknowledgements credits ARPA under Project Defender for AIO support with technical oversight by AFOSR. Other early papers include Gordon (1964), who reviews the history and research scope of AIO and notes that a $40 \mathrm{MHz}$ radar capability was being installed. The first $\mathrm{PhD}$ awarded using the Arecibo ISR (incoherent scatter radar) was that of Carlson (1965). This was followed by Thome (1966), Trost (1969), and Behnke (1970).

As mentioned above, the performance of the original $430 \mathrm{MHz}$ linefeed was found to be well below optimal. There are hints in the early reports that Professor Thomas "Tommy" Gold (Director, Cornell Center for Radiophysics and Space Research (CRSR) - CRSR managed AIO for Cornell) in particular pushed for a more efficient linefeed. In any case, a new circularly polarized $430 \mathrm{MHz}$ linefeed based on the evolution in design of radio astronomy linefeeds at $611 \mathrm{MHz}(\mathrm{Co}-$ hen and Perona, 1967) and at $318 \mathrm{MHz}$ (LaLonde and Harris, 1970) was constructed based on a detailed design study by Alan Love $(1973,1971)$. This feed, installed in January 1972, proved to be very successful - it is still in use and is a tribute to Alan Love's design genius - yielding a (radio astronomy) gain of about $61.5 \mathrm{dBi}\left(19.8 \mathrm{~K} \mathrm{Jy}^{-1}\right)$. The high gain of this feed, combined with a low temperature $(\sim 80 \mathrm{~K})$ receiver front-end, and high transmitter power uniquely yields ion-line incoherent scattering with daytime signal-to-noise ratios (SNR) greater than one from the base of the D-region $(\sim 80 \mathrm{~km})$ to nearly $1000 \mathrm{~km}$ altitude. For example, the Dregion ledge is easily visible to this radar (Mathews, 1984) as are D-region tidal winds (Mathews, 1976) and continuous "sporadic-E" (Morton et al., 1993; Mathews, 1998). Also, interestingly and uniquely for the incoherent scatter radars, near-field effects for this feed illuminating the $305 \mathrm{~m}$ dish are important up to approximately $300 \mathrm{~km}$, resulting in significant corrections to the incoherent scatter radar equation (Breakall and Mathews, 1982; Shen and Brice, 1973). Early results using the new linefeed were given by Behnke and Harper (1973) and others. 


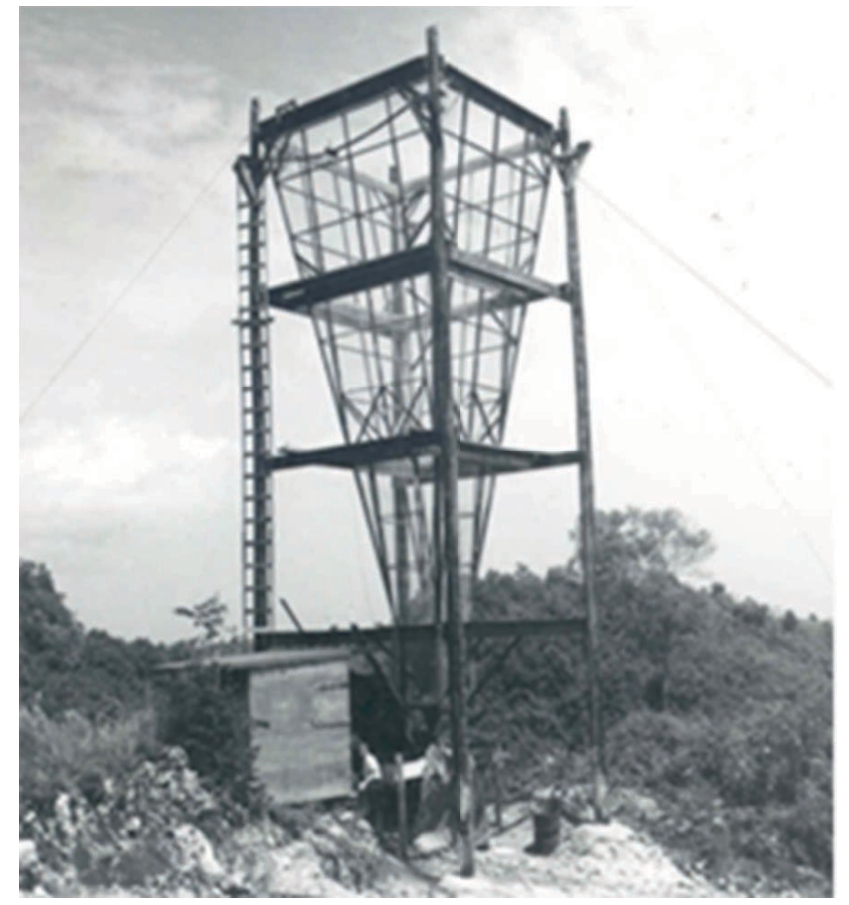

Figure 4. The first functioning radar feed at AIO. This $430 \mathrm{MHz}$ hornfeed was constructed to test the full radar system before the dish was completed. This feed had a $\sim 10^{\circ}$ half-power beamwidth and was in operation in mid-October 1962. It was used to receive the sun in transit and to obtain lunar echoes as the moon transited near zenith (Gordon, 1962a). Photo courtesy of Carmen G. SegarraSaavedra (Segarra-Saavedra, 2012).

\section{The AlO $40.12 \mathrm{MHz}$ radar}

The success of the original Bowles radar (Bowles, 1958) likely led to the decision to include a similar radar at AIO, though this is speculation and the mystery as to why this radar was installed at AIO remains. The proposal for this system was sent to AFOSR in early August 1962 and it was funded by 29 August 1962 (Gordon, 1962b). This radar, designed and built for AIO under ARPA funding (Gordon, 1962a), was initially to be installed in July 1964 but ultimately was commissioned in June 1965 (Gordon, 1965). This system employed four four-element Yagi antennas symmetrically arrayed around the $430 \mathrm{MHz}$ feed at the appropriate position below the paraxial surface, as shown in Fig. 5. The peak antenna gain was $36.9 \mathrm{dBi}$ and transmitted power was $1.2 \mathrm{MW}$ peak (50 kW average power) with the power supply and actual transmitter located adjacent to the $430 \mathrm{MHz}$ klystron and power vaults with RF delivered to the carriage house via 6-inch co-axial cable (Campbell and Muhleman, 1969; Thompson, 1970).

While there are hints that this radar was installed at AIO for ionospheric heating experiments and for incoherent scatter observations in conjunction with the $430 \mathrm{MHz}$ system (Watkins, 1967), it appears that the only published

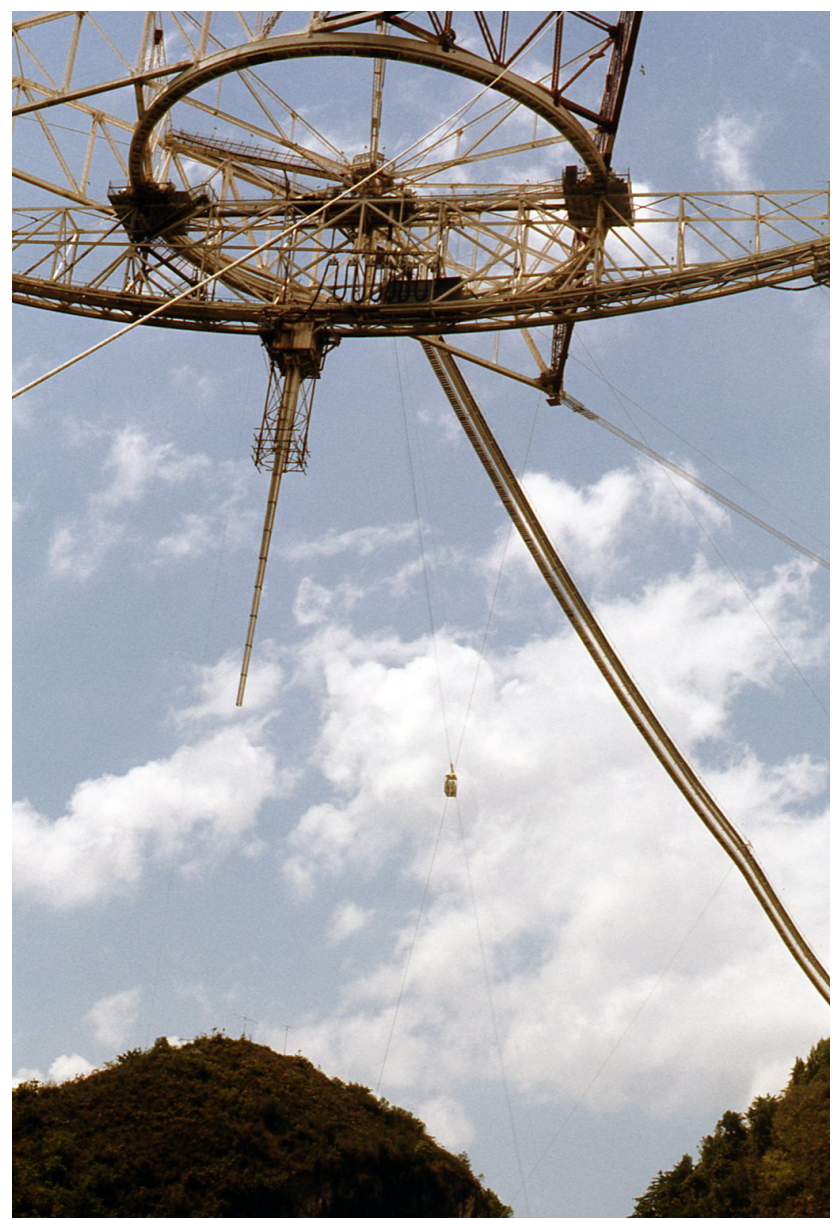

Figure 5. A picture from 13 May 1971 showing carriage house 1 (CH1) with the $40 \mathrm{MHz}$ radar feed system consisting of four Yagi antennas placed symmetrically around the original square crosssection $430 \mathrm{MHz}$ linefeed. Note the cable car giving convenient access to the platform relative to the catwalk which is located to the right and above the cable car in this photo. Photo courtesy of Cornell University and Arecibo Observatory.

ionospheric use was for ionospheric D- and E-region heating, which was strikingly successful (Showen, 1972). The Watkins report is a detailed study of the likely capabilities and uses of the radar with no mention of actual observations. It is likely that severe difficulties with the radar were encountered. An AIO funding proposal to AFOSR (Drake, 1968) reports without details the use of this radar in conjunction with the $430 \mathrm{MHz}$ system for incoherent scatter studies of the ionosphere; these results have not been located, adding to the mystery. The radar was also used to map the moon (Thompson, 1970) and in an attempt to detect scattering from the solar corona (Parrish, 1967). Campbell and Muhleman (1969) used this radar along with the $430 \mathrm{MHz}$ radar to measure the total electron content between Venus and Earth. The radar was decommissioned with the advent of the upgraded circular $430 \mathrm{MHz}$ linefeed (Figs. 8 and 9). 


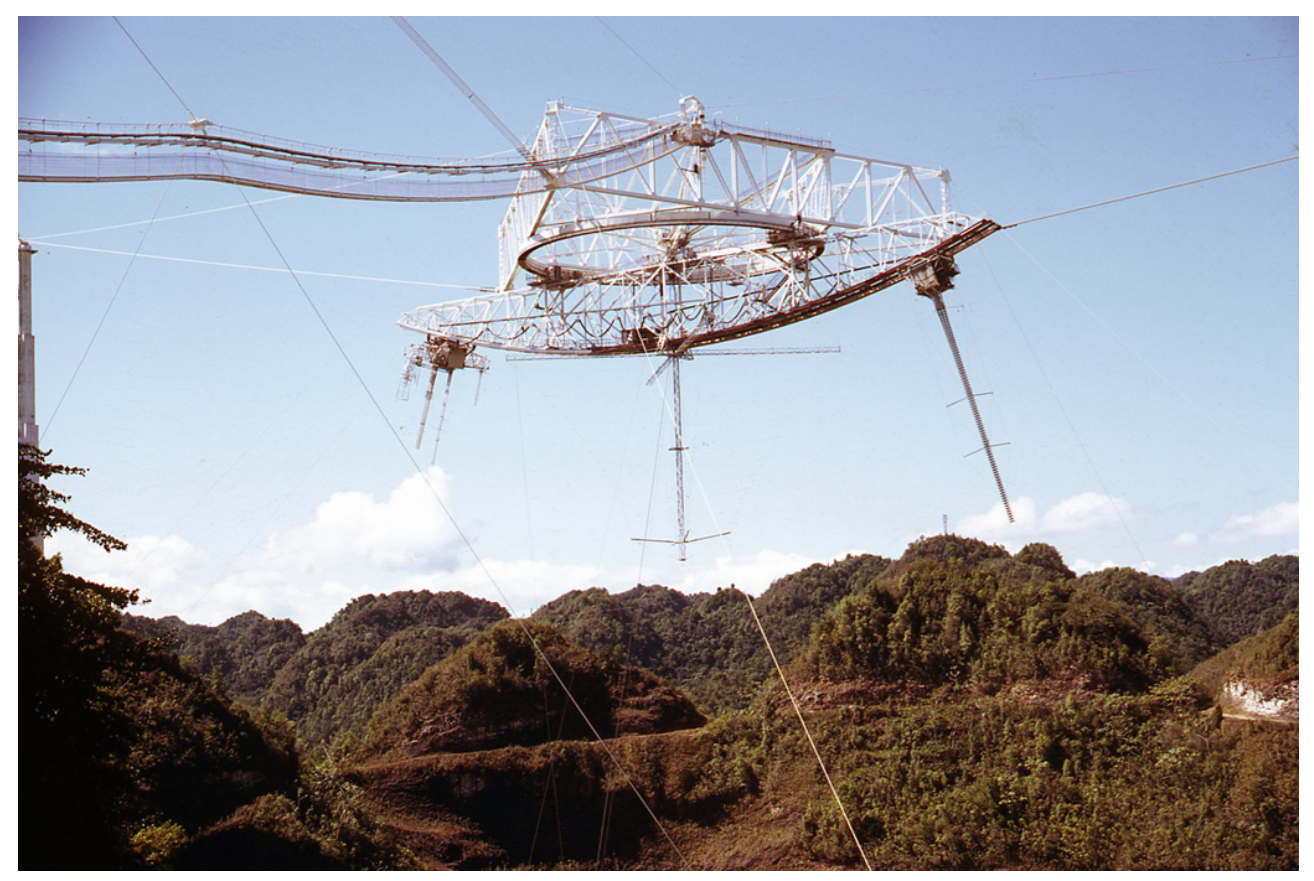

Figure 6. The Arecibo Observatory feeds in July 1972. The new $430 \mathrm{MHz}$ linefeed is mounted on carriage house \#1 to the right in this photo. In the center is the HF log-periodic feed for ionospheric heating experiments. To the left is carriage house \# 2 with various radio astronomy feeds including those at $318 \mathrm{MHz}$ (left, 40 feet long), $611 \mathrm{MHz}$ (right, 45 feet long), the far-right feed is likely $1667 \mathrm{MHz}$ test feed while the feeds at the far left are likely nested Yagis at $111 \mathrm{MHz}$ and $196 \mathrm{MHz}$ (D. B. Campbell, personal communication, 2013). Note the catwalk at the upper left of the photo. Photo courtesy of Cornell University and Arecibo Observatory.

However, the 6-inch coaxial cable from the transmitter room to the platform found use for delivering power to the first of the on-dish HF heater antennas. It is possible that the radar was decommissioned simply to use the co-axial cable to deliver HF power to the heating antenna. However there was an unsuccessful attempt to convert this system to $50 \mathrm{MHz}$ using a single large transmitter tube and a socket-located resonant cavity "tank" circuit provided by the NBS (National Bureau of Standards; or perhaps ESSA per the next section) in Boulder, Colorado (J. B. Hagen, personal communication, 2013).

\section{Early on-dish HF heating}

Ionospheric heating occurs when intense medium frequency through HF (high frequency) and even VHF (Showen, 1972) radio waves accelerate the electrons in the ionosphere causing collisional heating, plasma wave generation, and related interesting phenomena. As the heating or modification levels can be controlled, ionospheric modification experiments - rather than the usual incoherent scatter radar observations of the natural ionosphere - become possible. An example manifestation of ionospheric modification/heating is crossmodulation, whereby two radio frequency signals crossmodulate due to non-linear interaction in the ionosphere. The earliest example of cross-modulation is known as the Luxembourg effect. This arose in 1933 when the signal from the powerful $(150 \mathrm{~kW}$ at $252 \mathrm{KHz})$ Radio Luxembourg was heard superimposed on that of a weaker Swiss radio station at $652 \mathrm{kHz}$ (Huxley and Ratcliffe, 1949; Tellegen, 1933). The AIO incoherent scatter radar was uniquely capable of probing heating phenomena and thus use of the AIO dish for ionospheric heating was of great early interest.

Figure 6 shows the dual-polarization log-periodic HF feed system mounted at zenith above the Arecibo dish. This system, which was plagued by arcing and led to the Islote heater described next, replaced the $5.62 \mathrm{MHz}$ crossed-dipole with reflector (likely a dual-polarization, two-element Yagi) system described in Gordon et al. (1971). The Gordon et al. (1971) article describes O-mode HF ionospheric heating with this system at transmitter power levels of $100 \mathrm{~kW} \mathrm{CW}$ or pulsed (at any duty cycle) and a $\sim 10^{\circ}$ beamwidth. Carlson et al. (1972) elaborate that the HF transmitter was similar to those described by Utlaut (1970), who states that the HF transmitter was designed, built, and installed by staff of the Institute for Telecommunications Sciences of Environmental Science Services Administration (ESSA; later NOAA). L. M. LaLonde designed and built the feed. Unfortunately, a picture of the dipole heater feed mounted over the dish has not been located.

Gordon et al. (1971) described the effects of O-mode HF heating on the ionospheric F-region electron temperatures as derived using $430 \mathrm{MHz}$ incoherent scatter observations. 
Carlson et al. (1972) describe the effects of the HF heating on the incoherent scatter spectrum. In particular they describe enhanced ion-line scattering at the altitude at which the HF wave reflects from the ionosphere. They also reported strongly enhanced up/down-shifted plasma lines with additional features due to plasma parametric instabilities.

As the original crossed-dipole HF feed was restricted to a single frequency $(5.62 \mathrm{MHz})$, it was replaced by a dualpolarization log-periodic feed (Fig. 6) that yielded the frequency flexibility required for the ever-expanding needs of the HF heating community. Dias and Gordon (1973) report using the frequency agility of the new feed to study electron cyclotron lines in the HF-enhanced incoherent scatter spectrum. Gordon and Carlson (1974) reprise the results in the earlier papers cited above and introduce new results obtained using the new feed and a transmitter now capable of $160 \mathrm{~kW}$ power. Unfortunately the log-periodic feed would often "light-up" with arcs that quickly burned through the wires forming the feed, resulting in repeated failures. This issue, combined with the need for even higher power levels and greater ISR pointing flexibility (the HF feed restricted carriage house pointing to zenith angles greater than $\sim 4^{\circ}$ ) led to the design of the stand alone HF heater array that was located $\sim 17 \mathrm{~km} \mathrm{NNE}$ of AO at Islote on the coast of Puerto Rico.

In a rather unique use of the log-periodic feed Sulzer et al. (1982) used the heater HF transmitter at $12 \mathrm{~kW}$ peak power level and $3.155 \mathrm{MHz}$ frequency to provide the probing or "wanted" pulse for a D-region cross-modulation experiment where the $430 \mathrm{MHz}$ radar performed as the heater transmitter. This "inverted role" system successfully demonstrated wave interaction (cross-modulation) and is the only known example of UHF $(430 \mathrm{MHz})$ heating of the ionosphere D-region.

\section{The islote stand-alone HF heater}

In mid-1980, construction began on the Islote heater facility with operations commencing in September 1981 (Fejer et al., 1985). In its initial manifestation this system operated at frequencies of $3-12 \mathrm{MHz}$ with an effective radiated power (ERP) of up to $\sim 120 \mathrm{MW}$. This was accomplished with HF transmitters supplying up to $600 \mathrm{~kW}(4 \times 150 \mathrm{~kW}$ transmitters) continuous power, depending on the diesel generators and the state of the transmission lines to the two sets of $\sim 20 \mathrm{dBi}$ gain $4 \times 4 \log$ periodic antenna arrays shown in Fig. 7 (Isham et al., 2000; Fejer et al., 1985).

Transmission lines used in the first manifestation of this facility were open-wire pseudo-coaxial cables that resulted in severe mismatch and cross-coupling effects. These issues, along with diesel generator shortcomings, resulted in peak power limitations with a maximum at or below $400 \mathrm{~kW}$. The HF facility was upgraded in stages, with new transmission lines beginning in September 1983 (NAIC Newsletter
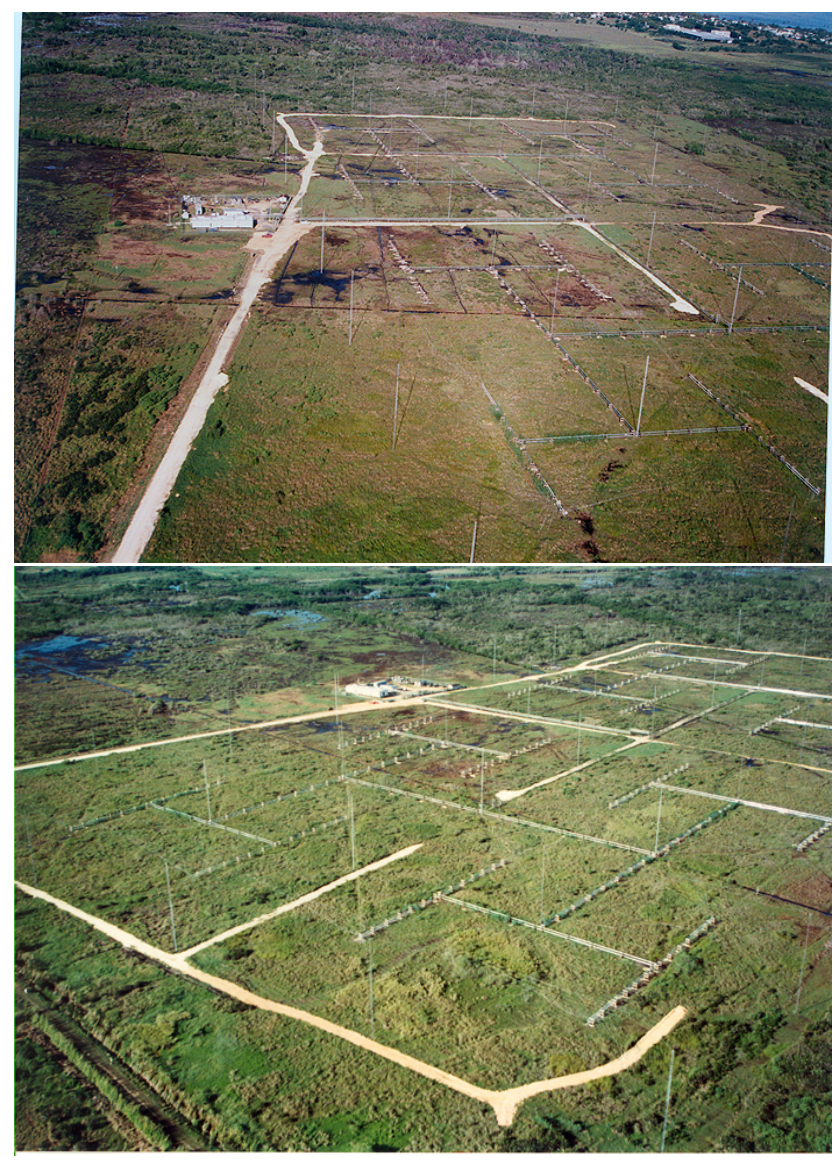

Figure 7. The Islote heater facility circa 1997. In these aerial views most of the two $4 \times 4 \log$ periodic antenna arrays is visible with the transmitter/control building to the left/top and the ocean just visible at the top right. The dual, closed coaxial "cable" (constructed from irrigation pipe) transmission line system to the center of each $\log$ periodic feed is clearly visible as are the support towers. The wire log periodic feeds are not visible but are suspended from four towers with two linear polarizations each driven from a separate transmission line. Photo courtesy of Cornell University and Arecibo Observatory.

No. 2, September 1983) with all upgrades completed in early 1997. These upgrades allowed for reliable use at the full $600 \mathrm{~kW}$ CW. Interestingly, this upgrade successfully replaced the old open wire pseudo-coax cables with coax formed using large irrigation pipes (NAIC/AO Newsletter No. 23, November 1997). Unfortunately, this facility was severely damaged by Hurricane Georges on 21-22 September 1998 (NAIC/AO Newsletter No. 26, November 1998) and this, combined with the government decision to return the wetlands on which the facility was located to natural state, led to decommissioning of the facility in 1999.

Early use of the Islote heater included the 25 November and 8 December 1981 observations of HF-enhanced plasma lines using the $140 \mathrm{~kW}$ peak-power $46.8 \mathrm{MHz}$ Max-Planck radar discussed in Sect. 7 (Fejer et al., 1983; Röttger et al., 
1981). The use of both the $430 \mathrm{MHz}$ and weaker $46.8 \mathrm{MHz}$ radars in the presence of ionospheric heating underscores the scientific versatility of AO. Fejer et al. (1984) report detection of Bragg scattering of the X-mode HF signal from the periodic irregularities, induced by $\mathrm{O}$-mode heating at the base of the F-region. In this scenario CW heating below the peak F-region plasma frequency results in a standing wave a result of the combined incident and reflected waves - with sufficient E-field magnitudes that the ponderomotive forces produce a corresponding modulation of the electron concentration profile at half the local HF O-mode wavelength. The heater is then used as pulsed transmitter in X-mode to probe the region, revealing the Bragg-scattering from the resultant $\Delta N / N \approx 10^{-4}$ ionospheric structuring.

Fejer et al. (1985) reviewed heater-related science from 1981-1984; this review excluded posters presented at the 1984 URSI GA in Florence, Italy. Topics discussed included what came to be known as SEE (Stimulated Electromagnetic Emission) that was discussed in more detail by Thidé et al. (1989). Isham et al. (2000) review the many scientific uses of this facility over its lifetime.

\section{Bi-static HF radar}

Gonzales and Woodman (1984) report the use of the Islote heater system as the transmitter component of a bistatic HF partial reflection radar with the receive antenna on the dish. The goal of these observations was the understanding of D-region turbulence processes. In these tests Gonzalez and Woodman transmitted complementary (orthogonal) code sequences using the Islote system operating at $\sim 200 \mathrm{~kW}$ peak power and over a $5-8 \mathrm{MHz}$ frequency range. The code sequence used was a repeated series of $8 \times 16$-baud, $18 \mu \mathrm{s} / \mathrm{baud}$ pulses. The received signal was sampled every $6 \mu$ s on the appropriate bandwidth. The use of the complementary code sequence allowed use of relatively short $(4 \mathrm{~ms})$ IPPs (InterPulse Periods) as the long coherence time of the E/F-region direct-reflection and multi-bounce returns from prior radar pulses to largely cancel, allowing much better processed SNR on the quite weak D-region partial reflections. The receive system featured a zenith-pointed, wide-band crosseddipole mounted at the parabolic focus of the dish. This antenna arrangement yielded a half-power beamwidth of $\sim 13^{\circ}$ at $5 \mathrm{MHz}$. As this antenna is difficult to see in the only photo available, this picture will be included only in web accessible materials for this paper.

As Gonzales and Woodman report, this system was used to determine 32-point power spectra for 256 ranges after coherent integration, decoding, and incoherent integration of the FFT spectrum. This system detected scattering layers from about $60 \mathrm{~km}$ through $130 \mathrm{~km}$, with the strongest layers centered at about $73 \mathrm{~km}, 81 \mathrm{~km}$, and $89 \mathrm{~km}$ altitudes. They also report scattering near $150 \mathrm{~km}$ range that they attribute to meteors in the side lobes - this assumption bears reexamination.

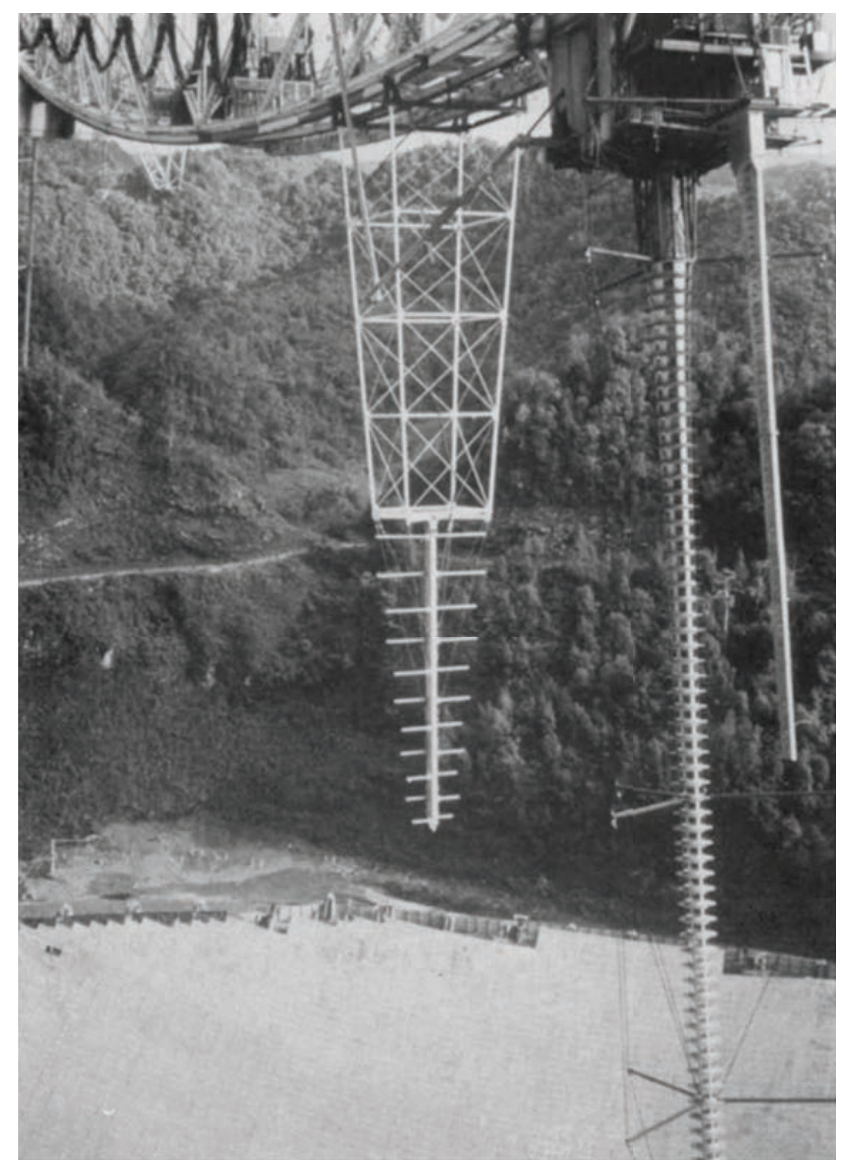

Figure 8. The Max Planck Institute for Aeronomy $46.8 \mathrm{MHz}$ SOUSY radar feed mounted downhill from carriage house $1(\mathrm{CH} 1)$ and towed by $\mathrm{CH} 1$. This was an 11-element log-periodic antenna with $45-55 \mathrm{MHz}$ frequency range and an $8 \mathrm{~dB}$ gain, yielding $60^{\circ}$ half-power beamwidth to efficiently illuminate the dish. The $430 \mathrm{MHz}$ radar line feed and $318 \mathrm{MHz}$ radio astronomy feed are mounted on the carriage house (Röttger et al., 1981).

\section{Max-Planck Institut für Aeronomie SOUSY 46.8 MHz MST radar}

Röttger et al. (1981) report the first pilot MST (Mesospheric, Stratospheric, Thermospheric) radar results from April and May 1980 using a $46.8 \mathrm{MHz} 4 \mathrm{~kW}$ peak power, 150 watt average power transmitter and the antenna configuration shown in Fig. 8. The $46.8 \mathrm{MHz}$ operating frequency was chosen, as interference was minimal at this frequency and remains in use today. The Figure 8 antenna system was a broadband 11-element log-periodic antenna with $45-55 \mathrm{MHz}$ operating bandwidth and an $8 \mathrm{dBi}$ gain over this range. The feed was located $12 \mathrm{~m}$ below the paraxial surface. The paraxial surface for the AO $265 \mathrm{~m}$ radius dish is half the radius or $133 \mathrm{~m}$; see Love (1971) for a complete description of the dish geometry and of linefeed antennas. At this frequency and feed location, the dish acts as parabolic reflector as the relative deviation of 
the sphere from the parabola with focus at a point is minimal. The peak gain of this system was $\sim 40 \mathrm{dBi}$.

This low-power MST radar system was used to observe ST (stratospheric, tropospheric) echoes. Perhaps surprisingly, it also detected mesospheric scattering from near $72 \mathrm{~km}$ and $80 \mathrm{~km}$ altitude. The $80 \mathrm{~km}$ mesospheric scattering layer exhibited apparent aspect sensitivity, while the lower layer faded away over about $80 \mathrm{~min}$. Sufficient SNR was available to measure winds over the $72-84 \mathrm{~km}$ range.

The success of the pilot low-power transmitter as reported by Röttger et al. (1981) quickly led to the late 1980 installation of a $30 \mathrm{~kW}$ peak power, $4 \%$ duty-cycle transmitter that was used for a series of lengthy joint UHF/VHF radar campaigns; the $140 \mathrm{~kW}$ peak power system reported by Fejer et al. (1983) appears to have been only temporarily available. Röttger et al. (1983) report the results of a campaign conducted over the period of 10 December 1980 through 18 January 1981. As before, scattering from $\sim 8-25 \mathrm{~km}$ (upper troposphere and lower stratosphere) and $\sim 60-82 \mathrm{~km}$ (mesosphere) was observed at least near local noon. While full day observations were conducted, most observations ran from 11:00-13:00 AST (Atlantic Standard Time, AST = UT - 4h). These observations often included the $430 \mathrm{MHz}$ incoherent scatter radar and, somewhat amazingly, this observational approach captured the effects of a type 4 solar X-ray flare on the mesosphere (Figure 1 of Röttger et al., 1983). This flare was thoroughly analyzed by Rastogi et al. (1988), who concluded that the enhanced VHF scattering that was observed was due to turbulent mixing of the flare-enhanced electron concentration profile, resulting in enhanced fluctuations at the VHF Bragg scale. The full D- and lower-E region electron concentration contours of this flare event are given in Figure 10 of Mathews (1984).

\section{Evolution of the current $46.8 \mathrm{MHz}$ radar}

As the SOUSY transmitters were located at AO on a temporary basis only, a transmitter with $50 \mathrm{~kW}$ peak power and $2 \%$ duty cycle was designed and built by Tycho Technology, Inc. (John Brosnahan) (NAIC Newsletter No. 1, 1 March 1983). It was finally installed and was operational as of June 1985 (NAIC Newsletter No. 5, June 1985). As this system was intended to operate at only $46.8 \mathrm{MHz}$, the Fig. 8 log-periodic feed was replaced by twin, dual-element (i.e., linear polarization) Yagi antennas located $9.3 \mathrm{~m}$ below the paraxial surface. The receiver system was also upgraded at this time. A description of the system prior to installation of the coaxial to the $430 \mathrm{MHz}$ line feed antenna system is given by Röttger et al. (1986).

The Yagi antenna system (photo not available) that replaced the Fig. 8 log-periodic feed was located $2.16^{\circ}$ "downhill" from the $430 \mathrm{MHz}$ beam-center and was also towed by $\mathrm{CH} 1$. However, this arrangement prevented common volume observations with the two radars and was super-

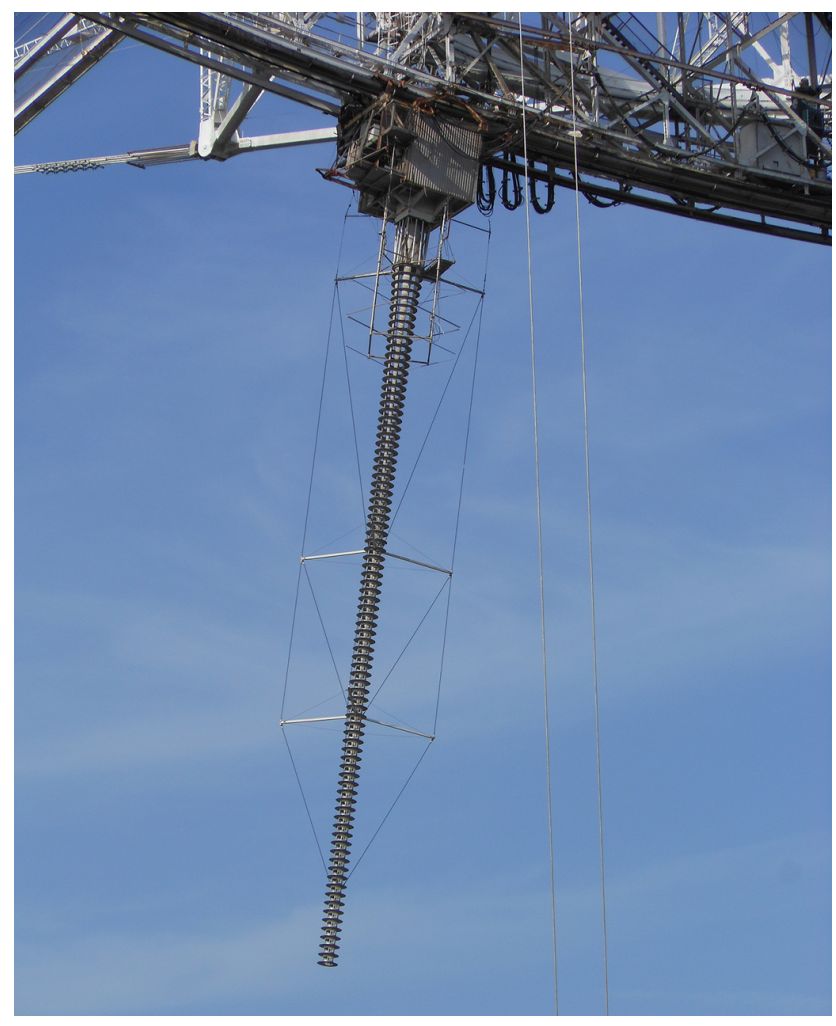

Figure 9. The modern $430 \mathrm{MHz}$ linefeed and coaxial $46.8 \mathrm{MHz}$ dual-polarization Yagi feeds as of August 2012. The 46.8 MHz feed is comprised of four, 3-element Yagi antennas and yields $\sim 1.4^{\circ}$ fullwidth at half-maximum beamwidth and $\sim 40 \mathrm{dBi}$ gain (Mathews et al., 2010). Photo by author.

seded in 1986 by the current arrangement seen in Fig. 9 (Isham et al., 2000). The upgraded $46.8 \mathrm{MHz}$ radar was only lightly used until computer technology reached the point that raw voltage returns over a significant range could be recorded for each radar pulse and be subjected to efficient post-observation analysis. This, along with the fortuitous coaxial $430 / 46.8 \mathrm{MHz}$ beams, enabled nearly unique meteor head-echo observations. This subject, pioneered by Chapin and Kudeki (1994) and Pellinen-Wannberg and Wannberg (1994), has become known as high-power, largeaperture (HPLA) meteor observations and was followed by the $430 \mathrm{MHz}$ radar work of Zhou et al. (1995) and Mathews et al. (1997). Importantly, Zhou et al. (1998) reported dualfrequency meteors with complex range-spread trail-echoes at VHF. This was followed by Mathews et al. (2010), who reported meteoroid fragmentation based on radio science aspects of individual meteors observed simultaneously by the V/UHF radars. This capability is nearly unique, with only the ALTAIR 160/422 MHz radar configured in a similar fashion (Close et al., 2002). The ALTAIR (ARPA Long-Range Tracking and Instrumentation Radar) system is located on the Kwajalein Atoll in the US Marshall Islands. 


\section{$102380 \mathrm{MHz}$ radar investigation of the lower atmosphere}

Radar scattering from clear air turbulence led to the use of the JRO (Jicamarca Radio Observatory) $50 \mathrm{MHz}$ radar in what became known as MST (Mesosphere, Stratosphere, Troposphere) radar observations of these regions (Woodman and Guillen, 1974; Rastogi and Woodman, 1974). The JRO observations led shortly thereafter to the first use of the AO $430 \mathrm{MHz}$ radar in an attempt to observe scattering from the stratosphere and lower mesosphere (Aso et al., 1977). Not unexpectedly they detected only scattering from the stratosphere, thus supporting initial ideas concerning UHF versus VHF scattering from turbulence-induced index of refraction fluctuations in the stratosphere relative to the mesosphere. Aso et al.'s (1977) observations were immediately followed by those reported by Farley et al. (1979), who also provide a short but comprehensive review of the subject to that point. Then Woodman (1980b) introduced new AO $430 \mathrm{MHz}$ stratospheric observations using the Arecibo-designed and built planetary radar decoder, a new radar controller, an array processor that allowed use of fast sampling, and a 32-bit, $1 \mu \mathrm{s} /$ baud complementary code pair that yielded 150-m range resolution and strong code sidelobe suppression. This code employed the intrinsic $1 \mathrm{MHz}$ bandwidth of the transmitter klystrons. These improvements allowed for the processing of 256 altitudes to spectra and thus winds with 150-m altitude resolution and approximately 2 -min time resolution after averaging.

The above-described evolution of MST radar and, specifically, the observations of the stratosphere using the AO $430 \mathrm{MHz}$ radar, set the stage for use of the AO $2380 \mathrm{MHz}$ planetary radar for similar measurements but at much more enhanced altitude resolution. However, the AO $2380 \mathrm{MHz}$ radar did not and does not have a fast transmit/receive switch and so low altitude observations must utilize a bi-static (or multi-static) antenna system. Woodman (1980a) argues that the $150-\mathrm{m}$ altitude resolution achieved with the $430 \mathrm{MHz}$ radar is sufficient for the study of waves and winds at stratospheric heights but does not resolve the details of the turbulent scattering layers. To this end, Woodman uniquely employed the $20 \mathrm{MHz}$ bandwidth, $2380 \mathrm{MHz}$ planetary radar, transmitting long pseudo-random codes to study the stratosphere. The required bi-static reception was achieved using the 30.5-m parabolic dish shown in Fig. 10. This dish was located $11 \mathrm{~km}$ north of AO at Higuillales (Los Caños) in the hills just above the town of Arecibo. It was built by AO under the direction of Rolf Dyce in 1975 specifically for S-band planetary radar interferometry. It cost $\sim \$ 300 \mathrm{~K}$ and was likely the 5th largest US radio telescope at that time (D. B. Campbell, personal communication, 2012). The Higuillales location was that of an earlier 15-m parabolic dish built by - and at the then residence of - the famed ham radio operator Sam Harris (W1FZJ) and his wife Helen (W1HOY). Sam Harris was the head receiver engineer for AO. He pio-

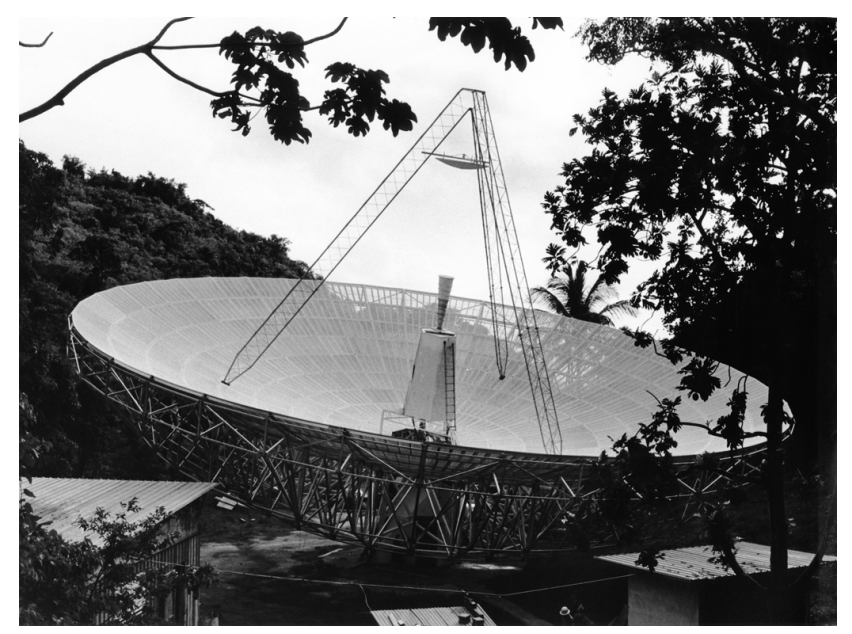

Figure 10. The Higuillales (Los Caños) $30.5 \mathrm{~m}$ parabolic dish used by Woodman (1980a) for S-band studies of stratospheric turbulence. Photo courtesy of Cornell University and Arecibo Observatory.

neered early moon bounce communications at $432 \mathrm{MHz}$ using this dish, as well as the main AO dish (DeMaw, 1965).

For these observations the $2380 \mathrm{MHz}$ radar was used at an average power level of $400 \mathrm{~kW}$ and potential resolution of $15 \mathrm{~m}$, although processing limitations yielded $30-\mathrm{m}$ resolution. The 30.5-m parabolic dish was outfitted with a just under $20 \mathrm{~K}$ maser receiver and, together, the bistatic system yielded an illuminated volume of $\sim 200 \mathrm{~m}$ horizontally and $\sim 600 \mathrm{~m}$ vertically. This unique and very powerful radar yielded 30-m resolution turbulence scattering RTI plots up to about $19 \mathrm{~km}$ altitude as the intersection of the two beams was adjusted. Scattering layers over the few hours of observations ranged in total thickness from $100 \mathrm{~m}$ to a few hundred meters but with peak scattering "cells" at or smaller than the $30 \mathrm{~m}$ range resolution. Coverage was limited by the common volume of the two antennas and by processing limitations. Ierkic et al. (1990) reports on further $2380 \mathrm{MHz}$ radar observations of lower stratospheric turbulent scattering reaching to nearly $20 \mathrm{~km}$ altitude. In this effort the range resolution was improved to about $20 \mathrm{~m}$ with $15 \mathrm{~s}$ time resolution.

\section{$11430 \mathrm{MHz}$ horn feed and the Gregorian feed}

While for political reasons rocket campaigns will likely never occur again from Puerto Rico, the "El Coqui" rocket campaign, conducted from 18 May through 13 July 1992 (the COQUI DOS campaign occurred in 1998 as described below) included chemical releases into the natural F-region ionosphere as well as combined HF-heating of the ionosphere, chemical releases into the heated volume, and HF/VHF-radar and ISR diagnostics of the modified ionosphere (Djuth et al., 1995). This campaign was organized under NASA by Dr. David L. Reasoner and all AO activities in 
this campaign were conducted under a blanket proposal for all participants (F. T. Djuth, personal communication, 2013). Of particular interest is that for the first time two $430 \mathrm{MHz}$ radar beams were employed. These were the $\mathrm{CH} 1$ linefeed ( $\sim 61.1 \mathrm{dBi}$ gain, $80 \mathrm{~K}$ system temperature) discussed in Sect. 2, and a fixed zenith-looking $430 \mathrm{MHz}$ hornfeed ( $\sim 51 \mathrm{dBi}$ gain, unknown system temperature) mounted just below the paraxial surface. Unfortunately, no pictures of this $430 \mathrm{MHz}$ hornfeed - or any published data derived from this system - have been found. However, the author recalls seeing ISR power profiles from this system and recently found this feed "retired" under the dish.

Perhaps as inspired by the limited success of the $430 \mathrm{MHz}$ hornfeed and the successful development of the necessary power-splitter, when the spherical aberration-correcting Gregorian system was designed, provisions were made for a second $430 \mathrm{MHz}$ radar beam. Unlike the original "point" hornfeed that had a gain of $\sim 51 \mathrm{dBi}$ because of spherical aberration, the Gregorian feed (with exact aberration correction and suitable illumination of the dish) has a gain of $\sim 59.3 \mathrm{dBi}$ with a total system temperature as low as $\sim 65 \mathrm{~K}$. This system became available in early June 2001 (NAIC Newsletter \#33, October 2001) and has been steadily used since then e.g., Gong et al. (2012). The Gregorian and linefeed systems together enable beam-swinging ionospheric vector wind and electric field observations and other unique observations as described by Gong et al. (2012).

\section{2}

\section{Various other radar experiments}

In addition to the specific radar developments outlined above, Arecibo Observatory has hosted and continues to host a wide range of nearby collaborating radars. Perhaps the greatest single assembly of such radars was associated with the "El Coqui" rocket campaign (1992) discussed in Sect. 10. Djuth's (1995) Table 1 lists an HF radar (SRI International), two bi-static HF radars (Los Alamos and NRL), two VHF radar interferometer systems (Cornell and Geospace Research, Inc.), and a digisonde (Phillips Lab/SRI International) all of which diagnosed various aspects of the heated volume and of the barium releases into the heated region of the ionosphere, e.g., Bernhardt et al. (1995).

Examples of other uses of the Arecibo radar systems include a comparison between $430 \mathrm{MHz}$ ISR D- and lower-E region winds with those determined by a classical meteor wind radar located near Ramey, Puerto Rico (Mathews et al., 1981) and an attempt to use the moon as a radar calibration target (Mathews et al., 1988). Palmer et al. (1997) deployed three $430 \mathrm{MHz}$ Yagi-Uda antenna arrays, forming an interferometer (the Arecibo Spatial Interferometry System or ASIS) at about $327 \mathrm{~m}$ from the center of the dish to bi-statically probe the troposphere over about $3-10 \mathrm{~km}$ altitude. The bistatic mode was necessitated by limitations of the T/R switch on the $430 \mathrm{MHz}$ system and successfully produced wind re- sults. While there were plans to continue these observations with an enhanced ASIS system, this appears not to have happened. Tepley's (1997) Table 1 gives a summary of the AO radar capabilities circa 1997.

A series of campaign-mode observations, the Caribbean Ionosphere Campaign (Kelley et al., 2000) and COQUI DOS (II), occurred in 1998 and 1999. During these campaigns two HF radars - the Cornell University Portable Radar Interferometer (CUPRI; $46.9 \mathrm{MHz}, 40 \mathrm{~kW}$ peak power) and the University of Illinois radar $(49.92 \mathrm{MHz}, 35 \mathrm{~kW}$ peak power) were deployed near the south coast of Puerto Rico such that the perpendicular-to-B zone of the E- and F-regions was visible to the north of AO (Swartz et al., 2000a). The HF radar observations revealed F-region FAI (Field-Aligned Irregularity) scattering (Swartz et al., 2000b) at a slant range of 400$800 \mathrm{~km}$ that was apparently associated with spread-F (instability) structures observed over $\mathrm{AO}$ with the incoherent scatter radar (ISR). A particularly strong FAI-producing event was observed on 17 February 1998 (Swartz et al., 2000a). Using high-resolution ISR data, Mathews et al. (2001) demonstrated the presence of highly organized, sub-kilometer horizontal/vertical scale F-region structures over AO during the 17 February 1998 spread-F event. While not commonvolume, this series of observations clearly established the link between F-region FAI-scattering structures and associated small-scale structures observed with ISR. Only AO has the signal-to-noise ratio necessary to observe details of these features, which were first reported at the Japan MU radar (Fukao et al., 1988).

An ongoing common volume exploration of coherent Eregion quasi-periodic echoes (QPEs) - also FAI scattering structures - and the underlying ionospheric features seen in the incoherent scatter radar was initiated by Hysell et al. (2004) using a $30 \mathrm{MHz}$ interferometric imaging radar deployed on St. Croix, US Virgin Islands. From St. Croix, this system is sensitive to E-region magnetic-field-aligned echoing structures in a volume over Puerto Rico that includes the AO $430 \mathrm{MHz}$ radar beam. The results of these common volume observations of QPE/Sporadic-E are updated in Hysell et al. (2009). A second VHF imaging radar to be located on the Caribbean island of Guadeloupe in the Leeward Islands will be sensitive to field-aligned scatterers in the Fregion over Arecibo. Various radars looking over Arecibo from these islands were deployed in the past for the "El Coqui" rocket campaign mentioned above.

Finally, a new "on-dish" HF heater is now being installed at $\mathrm{AO}$ for operations to commence in 2013 if all goes well.

\section{Some mysteries?}

In writing this history the author admits to gaps that, hopefully, the readers will fill by contacting the author, who promises a suitable update to this paper. The largest known gap is why the $40 \mathrm{MHz}$ radar system, built specifically 
for $\mathrm{AIO}$, was installed at $\mathrm{AIO}$ and then abandoned with no reported incoherent scatter observations of the ionosphere. In fact the only known ionospheric usage was that of Showen (1972). Further, the system was abandoned by 1972 - probably to free the 6-inch coaxial cable to feed the on-dish HF heater antenna described in Sect. 4 - only to have a substantially less powerful $46.8 \mathrm{MHz}$ system brought in by 1980 . Had the early report by Watkins (1967) on the ionospheric uses of the $40 \mathrm{MHz}$ system been seriously considered, the radar would likely have led to discoveries that anticipated MST radar and to HPLA radar meteor research. Watkins must certainly have been aware of the latter, given his home institution was the Royal Radar Establishment (Malvern UK) and his involvement with Greenhow in VHF/UHF study of meteors (Greenhow et al., 1962; Greenhow and Watkins, 1964). Perhaps the answer to this is just that this radar was unreliable and could not be maintained?

Perhaps other mysteries or answers will come to light in two autobiographical memoirs that the author just learned of but has not yet seen. One is that of Alan F. Kay, the designer of the original square cross-section $430 \mathrm{MHz}$ linefeed (Kay, 1961, 2008), while the other is that of Thomas "Tommy" Gold (2012), who figured significantly in the early days of AIO especially (as discussed in Sect. 2) as he was the Director of the Cornell Center for Radiophysics and Space Research (CRSR) that managed AIO for Cornell. We additionally note the recently published and very significant history of AO written by Carmen Segarra-Saavedra (2012). Other histories are apparently in preparation.

\section{Conclusions}

As indicated above and as is inevitably the case, this history remains incomplete, with gaps and mysteries that the community should fill and solve. In writing it the author became acutely aware of the importance of documenting the science-driven evolution of facilities like Arecibo observatory. Further, and most importantly, this history highlights the several generations of students, engineers, and scientists - from many areas of interest and from around the world who gathered at the observatory and who made and make the Observatory so intellectually stimulating. Arecibo Observatory will surely continue to be a scientific, engineering, and educational focus point well into the future as it is adapted to pursue new goals.

Acknowledgements. The author gratefully acknowledges the following individuals for their input to this history: K. L. Bowles, D. B. Campbell, H. C. Carlson, D. F. Farley, S. Gonzalez, J. B. Hagen, T. W. Thompson, J. Röttger, R. M. Robinson, Carmen G. Segarra-Saavedra, and M. P. Sulzer. Monica S. Mathews capably edited the many versions of this paper. The author also acknowledges the amazing opportunities, friends, and colleagues afforded him through his long - now nearly $44 \mathrm{yr}$ - association with Arecibo Observatory and its staff. This association was due in large part to the kind and continuous funding from NSF for use of Arecibo Observatory in the author's research activities. This particular effort was supported under grants ATM 07-21613 and ATM 12-02019 to the Pennsylvania State University.

Edited by: K. Schlegel

Reviewed by: D. Campbell and one anonymous referee

\section{References}

Altschuler, D. R.: The National Astronomy and Ionosphere Center's (NAIC) Arecibo Observatory in Puerto Rico, in: ASP Conference Series, Single-Dish Radio Astronomy: Techniques and Applications, Arecibo Observatory, 2002.

Aso, T., Kato, S., and Harper, R. M.: Arecibo middle atmosphere experiment, Geophys. Res. Lett., 4, 10-12, doi:10.1029/GL004i001p00010, 1977.

Behnke, R. A.: Vector Measurements of the ion transport velocity with applications to F-region dynamics, Ph.D. thesis, Rice University, 1970.

Behnke, R. A. and Harper, R. M.: Vector measurements of F Region ion transport at Arecibo, J. Geophys. Res., 78, 8222-8234, doi:10.1029/JA078i034p08222, 1973.

Bernhardt, P. A., Siefring, C. L., Rodriguez, P., Haas, D. G., Baumback, M. M., Romero, H. A., Solin, D. A., Djuth, F. T., Duncan, L. M., Hunton, D. E., Pollock, C. J., Sulzer, M. P., Tepley, C. A., Wagner, L. S., and Goldstein, J. A.: The ionospheric focused heating experiment, J. Geophys. Res., 100, 17331-17345, doi:10.1029/94JA01887, 1995.

Berth, D. F.: An eye and ear to space: Engineering the telescope, in: Cornell Quarterly, Vol. 1 (summer), Cornell University, Ithaca NY, 24-29, 1966.

Bowles, K. L.: Observation of vertical-incidence scatter from the ionosphere at $41 \mathrm{Mc} / \mathrm{sec}$, Phys. Rev. Lett., 1, 454-455, 1958.

Breakall, J. K. and Mathews, J. D.: A theoretical and experimental investigation of antenna near-field effects as applied to incoherent backscatter measurements at Arecibo, J. Atmos. Terr. Phys., 44, 449-454, 1982.

Buderi, R.: The invention that changed the world: how a small group of radar pioneers won the Second World War and launched a technological revolution, The Sloan Technology Series, Simon \& Schuster, New York, 575 pp., ISBN: 0-684-81021-2, 1996.

Butrica, A.: Oral History Transcript - Dr. William Gordon: 28 November 1994, Oral Histories at the Niels Bohr Library \& Archives, http://www.aip.org/history/ohilist/22789.html, last access: March 2013, 1994.

Butrica, A. J.: To See the Unseen: A History of Planetary Radar Astronomy, The NASA History Series, NASA History Office, 301 pp., 1996.

Campbell, D. B. and Muhleman, D. O.: Measurements of the electron content of the interplanetary medium between Earth and Venus, J. Geophys. Res., 74, 1138-1143, doi:10.1029/JA074i005p01138, 1969.

Carlson, H. C.: Ionospheric Heating by Magnetic Conjugate Point Photoelectrons as Observed at Arecibo, Ph.D. thesis, Cornell, 1965.

Carlson, H. C., Gordon, W. E., and Showen, R. L.: High frequency induced enhancements of the incoherent scatter 
spectrum at arecibo, J. Geophys. Res., 77, 1242-1250, doi:10.1029/JA077i007p01242, 1972.

Caryotakis, G.: High power klystrons: Theory and practice at the Stanford Linear Accelerator Center, Stanford Linear Accelerator Center, SLAC-PUB 10620, 139 pp., 2005.

Chapin, E. and Kudeki, E.: Radar interferometric imaging studies of long-duration meteor echoes observed at Jicamarca, J. Geophys. Res., 99, 8937-8949, doi:10.1029/93JA03198, 1994.

Clarey, K. T.: An eye and ear to space: The man who developed Arecibo, in: Cornell Quarterly, Vol. 1 (summer), Cornell University, Ithaca NY, 22-23, 1966.

Close, S., Oppenheim, M., Hunt, S., and Dyrud, L.: Scattering characteristics of high-resolution meteor head echoes detected at multiple frequencies, J. Geophys. Res., 107, SIA 9-1-SIA 9-12, 2002.

Cohen, M. H.: Genesis of the 1000-Foot Arecibo Dish, J. Astron. Hist. Herit., 12, 141-152, 2009.

Cohen, M. H. and Perona, G. E.: A correcting feed at $611 \mathrm{MHz}$ for the AIO reflector, IEEE Trans. Ant. Prop., AP-15, 482-483, doi:10.1109/TAP.1967.1138943, 1967.

Delaney, W. P. and Ward, W. W.: Radar development at Lincoln Laboratory: An overview of the first fifty years, Lincoln Lab. J., 12, 147-166, 2000.

DeMaw, D.: The story of El Radar: The Moon and back on $432 \mathrm{Mc}$, QST, 49, 24-27, 1965.

Dias, L. and Gordon, W. E.: Observation of electron cyclotron lines enhanced by HF radio waves, J. Geophys. Res., 78, 1730-1732, doi:10.1029/JA078i010p01730, 1973.

Djuth, F. T.: Final Report Contract NAS8-39075: 21 August 1991 through 30 June 1994, Radar Investigations of Barium releases over Arecibo Observatory, Puerto Rico, NASA GRI-CR-957110, 162 pp., 1995.

Djuth, F. T., Sulzer, M. P., Elder, J. H., and Groves, K. M.: The CRRES AA 2 Release: HF wave-plasma interactions in a dense $\mathrm{Ba}^{+}$cloud, J. Geophys. Res., 100, 17347-17366, doi:10.1029/94JA02295, 1995.

Drake, F. D.: Proposal to the Air Force Office of Scientific Research for the Continuation of Contract F44-620-67-C-0066, Research in Ionospheric Physics and Radar-Radio Astronomy, 1 October 1968 through 30 September 1969, Center for Radiophysics and Space Research, Cornell University, 118 pp., 1968.

Editor, News: Research Facilties and Programs: The Arecibo Observatory, Phys. Today, 17, 66-67, doi:10.1063/1.3051375, 1964.

Farley, D. T., Swartz, W. E., LaHoz, C., and Balsley, B. B.: Tropical winds measured by the Arecibo radar, J. Appl. Meteor., 18, 227-230, doi:10.1175/15200450(1979)018<0227:TWMBTA>2.0.CO;2, 1979.

Fejer, J. A., Ierkic, H. M., Woodman, R. F., Röttger, J., Sulzer, M. P., Behnke, R. A., and Veldhuis, A.: Observations of the HF-Enhanced plasma line with a $46.8-\mathrm{MHz}$ radar and reinterpretation of previous observations with the $430-\mathrm{MHz}$ radar, J. Geophys. Res., 88, 2083-2092, doi:10.1029/JA088iA03p02083, 1983.

Fejer, J. A., Djuth, F. T., and Gonzales, C. A.: Bragg backscatter from plasma inhomogeneities due to a powerful ionospherically reflected radio wave, J. Geophys. Res., 89, 9145-9147, doi:10.1029/JA089iA10p09145, 1984.

Fejer, J. A., Gonzales, C. A., Ierkic, H. M., Sulzer, M. P., Tepley, C. A., Duncan, L. M., Djuth, F. T., Ganguly, S., and Gordon,
W. E.: Ionospheric modification experiments with the Arecibo Heating Facility, J. Atmos. Sol.-Terr. Phys., 47, 1165-1179, doi:10.1016/0021-9169(85)90086-8, 1985.

Fukao, S., McClure, J. P., Ito, A., Sato, T., Kimura, I., Tsuda, T., and Kato, S.: First VHF radar observation of midlatitude F-region field-aligned irregularities, Geophys. Res. Lett., 15, 768-771, 1988.

Gold, T.: Taking the Back off the Watch: A Personal Memoir, Springer, 249 pp., ISBN: 978-3642275876, 2012.

Gong, Y., Zhou, Q., Zhang, S., Aponte, N., Sulzer, M. P., and Gonzalez, S.: Midnight ionosphere collapse at Arecibo and its relationship to the neutral wind, electric field, and ambipolar diffusion, J. Geophys. Res., 117, A08332, doi:10.1029/2012JA017530, 2012.

Gonzales, C. A. and Woodman, R. F.: Pulse compression techniques with application to HF probing of the mesosphere, Radio Sci., 19, 871-877, doi:10.1029/RS019i003p00871, 1984.

Gordon, W. E.: Incoherent scattering of radio waves by free electrons with applications to space exploration by radar, URSI/IRE Fall Meeting, Penn State University, 20-22 October 1958a.

Gordon, W. E.: Incoherent scattering of radio waves by free electrons with applications to space exploration by radar, Proc. Inst. Radio Engrs., 46, 1824-1829, 1958b.

Gordon, W. E.: Summary Technical Report No. 5, Research in Ionospheric Physics, Arecibo Ionospheric Observatory, Center for Radiophysics and Space Research, Cornell University, 58 pp., 1962a.

Gordon, W. E.: Summary Technical Report No. 2, Research in Ionospheric Physics, Arecibo Ionospheric Observatory, Center for Radiophysics and Space Research, Cornell University, 22 pp., 1962b.

Gordon, W. E.: Arecibo Ionospheric Observatory, Science, 146, 2630, doi:10.1126/science.146.3640.26, 1964.

Gordon, W. E.: Summary Technical Report No. 7, Research in Ionospheric Physics, Arecibo Ionospheric Observatory, Center for Radiophysics and Space Research, Cornell University, 1965.

Gordon, W. E. and Carlson, H. C.: Arecibo heating experiments, Radio Sci., 9, 1041-1047, doi:10.1029/RS009i011p01041, 1974.

Gordon, W. E., Booker, H. G., and Nichols, B.: Engineering report of the School of Electrical Engineering, 3, Cornell University, Ithaca NY, 1958.

Gordon, W. E., Showen, R., and Carlson, H. C.: Ionospheric Heating at Arecibo: First Tests, J. Geophys. Res., 76, 7808-7813, doi:10.1029/JA076i031p07808, 1971.

Greenhow, J. S. and Watkins, C. D.: The characteristics of meteor trails observed at a frequency of $300 \mathrm{Mc} / \mathrm{s}$, J. Atmos. Terr. Phys., 26, 539-558, 1964.

Greenhow, J. S., Sutcliffe, H. K., and Watkins, C. D.: Radar observations of meteor echoes at a frequency of $1300 \mathrm{Mc} / \mathrm{s}$, Nature, 193, 1036-1037, 1962.

Hagen, J. B.: Arecibo $430 \mathrm{MHz}$ radar system: Operation and maintenance manual (2nd Edn.), Arecibo Observatory, 134 pp., 2005.

Huxley, L. G. H. and Ratcliffe, J. A.: A survey of ionospheric crossmodulation (wave interaction or Luxembourg effect), Proceedings of the IEE - Part III: Radio and Communication Engineering, 96, 433-440, doi:10.1049/pi-3.1949.0093, 1949.

Hysell, D. L., Larsen, M. F., and Zhou, Q. H.: Common volume coherent and incoherent scatter radar observations of mid-latitude sporadic E-layers and QP echoes, Ann. Geophys., 22, 3277- 
3290, doi:10.5194/angeo-22-3277-2004, 2004.

Hysell, D. L., Nossa, E., Larsen, M. F., Munro, J., Sulzer, M. P., and González, S. A.: Sporadic E layer observations over Arecibo using coherent and incoherent scatter radar: Assessing dynamic stability in the lower thermosphere, J. Geophys. Res., 114, A12303, doi:10.1029/2009JA014403, 2009.

Ierkic, H. M., Woodman, R. F., and Perillat, P.: Ultrahigh vertical resolution radar measurements in the lower stratosphere at Arecibo, Radio Sci., 25, 941-952, doi:10.1029/RS025i005p00941, 1990.

Isham, B., Tepley, C. A., Sulzer, M. P., Zhou, Q. H., Kelley, M. C., Friedman, J. S., and González, S. A.: Upper atmospheric observations at the Arecibo Observatory: Examples obtained using new capabilities, J. Geophys. Res., 105, 18609-18637, doi:10.1029/1999JA900315, 2000.

Kay, A. F.: A line source feed for a spherical reflector, Air Force Cambridge Research Lab, AFCRL 529, 1961.

Kay, A. F.: Militarist Millionaire Peacenik: Memoir of a Serial Entrepreneur, Cosimo Books, 240 pp., ISBN: 978-1602067547, 2008.

Kelley, M. C., Makela, J. J., Swartz, W. E., Collins, S. C., Thonnard, S., Aponte, N., and Tepley, C. A.: Caribbean Ionosphere Campaign, Year One: Airglow and plasma observations during two intense mid-latitude spread-F events, Geophys. Res. Lett., 27, 2825-2828, 2000.

LaLonde, L. M.: The upgraded Arecibo Observatory, Science, 186, 213-218, doi:10.1126/science.186.4160.213, 1974.

LaLonde, L. M. and Harris, D. E.: A high-performance line source feed for the AIO spherical reflector, IEEE Trans. Ant. Prop., AP18, 41-48, doi:10.1109/TAP.1970.1139608, 1970.

Love, A. W.: Arecibo $430 \mathrm{MHz}$ feed development study final project report, Autonetics (Division of North American Rockwell Corp), C70-112.6/301, 144 pp., 1971.

Love, A. W.: Scale model development of a high efficiency dual polarized line feed for the Arecibo spherical reflector, IEEE Trans. Ant. Prop., 21, 628-639, doi:10.1109/TAP.1973.1140555, 1973.

Mathews, J. D.: Measurements of the diurnal tides in the 80- to 100$\mathrm{km}$ altitude range at Arecibo, J. Geophys. Res., 81, 4671-4677, doi:10.1029/JA081i025p04671, 1976.

Mathews, J. D.: The Incoherent Scatter Radar as a tool for studying the Ionospheric D region, J. Atmos. Terr. Phys., 46, 975-986, 1984.

Mathews, J. D.: Sporadic E: Current views and recent progress, J. Atmos. Sol.-Terr. Phys., 60, 413-435, 1998.

Mathews, J. D., Sulzer, M. P., Tepley, C. A. R., Bernard, J. L., Fellous, Glass, M., Massebeauf, M. S., Ganguly, Harper, R. M., Behnke, R. A., and Walker, J. C. G.: A comparison between Thomson scatter and meteor radar wind measurements in the 65 $105 \mathrm{~km}$ altitude region at Arecibo, Planet. Space Sci., 29, 341348,1981

Mathews, J. D., Breakall, J. K., and Sulzer, M. P.: The Moon as a calibration target of convenience for VHF-UHF radar systems, Radio Sci., 23, 1-12, 1988.

Mathews, J. D., Meisel, D. D., Hunter, K. P., Getman, V. S., and Zhou, Q.: Very high resolution studies of micrometeors using the Arecibo $430 \mathrm{MHz}$ radar, Icarus, 126, 157-169, 1997.

Mathews, J. D., Gonzalez, S., Sulzer, M. P., Zhou, Q.-H., Urbina, J., Kudeki, E., and Franke, S.: Kilometer-scale layered structures inside spread-F, Geophys. Res. Lett., 28, 4167-4170, 2001.
Mathews, J. D., Briczinski, S. J., Malhotra, A., and Cross, J.: Extensive meteoroid fragmentation in V/UHF radar meteor observations at Arecibo Observatory, Geophys. Res. Lett., 37, L04103, doi:10.1029/2009GL041967, 2010.

Morton, Y.-T., Mathews, J. D., and Zhou, Q.: Further evidence for a 6-h tide above Arecibo, J. Atmos. Terr. Phys., 55, 459-465, doi:10.1016/0021-9169(93)90081-9, 1993.

Palmer, R. D., Larson, M. F., Howell, P. B., Cho, J. Y. N., Narayanan, R. M., and Kelley, M. C.: A new spatial interferometry capability using the Arecibo 430-MHz radar, Radio Sci., 32, 749-755, doi:10.1029/96RS03500, 1997.

Parrish, A.: Solar radar experiments, Center for Radiophysics and Space Research, Center for Radiophysics and Space Research, Report CRSR-300, Cornell University, 1967.

Pellinen-Wannberg, A. and Wannberg, G.: Meteor observations with the European incoherent scatter UHF radar, J. Geophys. Res., 99, 11379-11390, 1994.

Rankin, J. M.: Remembering the Early Days of Pulsars at the Arecibo Ionospheric Observatory, AIP Conf. Proc., 983, 166167, doi:10.1063/1.2900137, 2008.

Rastogi, P. K. and Woodman, R. F.: Mesospheric studies using the Jicamarca incoherent scatter radar, J. Atmos. Terr. Phys., 36, 1217-1231, doi:10.1016/0021-9169(74)90109-3, 1974.

Rastogi, P. K., Mathews, J. D., Ying, W.-P., and Röttger, J.: Simultaneous VHF and UHF radar observations of the mesosphere at Arecibo during a solar flare: A check on the gradient-mixing hypothesis, Radio Sci., 23, 97-105, doi:10.1029/RS023i002p00097, 1988.

Robinson, R. M., Eyken, A. v., and Farley, D. T.: Fiftieth anniversary of the first incoherent scatter radar experiment, EOS Trans. AGU, 90, 267, doi:10.1029/2009EO310005, 2009.

Röttger, J., Czechowsky, P., and Schmidt, G.: First low-power VHF radar observations of tropospheric, stratospheric and mesospheric winds and turbulence at the Arecibo Observatory, J. Atmos. Terr. Phys., 43, 789-800, 1981.

Röttger, J., Czechowsky, P., Ruster, R., and Schmidt, G.: VHF radar observations of wind velocities at the Arecibo Observatory, J. Geophys., 52, 34-39, 1983.

Röttger, J., Ierkic, H. M., Zimmerman, R. K., and Hagen, J. B.: Investigations of the lower and middle atmosphere at the Arecibo Observatory and a description of the new VHF radar project, in: Handbook for MAP, Third Workshop on Technical and Scientific Aspects Of MST Radar - Handbook for MAP Vol. 20, Aguadilla, Puerto Rico, 349-358, 1986.

Segarra-Saavedra, C. G.: Observatorio de Arecibo: Origen y Desarrollo, Publicaciones Puertorriquenas, Incorporated, ISBN-13: 9781935145417, 2012

Shen, J. and Brice, N.: Near-field gain calibration for large spherical antennas, IEEE Trans. Ant. Prop., 21, 787-792, doi:10.1109/TAP.1973.1140594, 1973.

Showen, R. L.: Artificial Heating of the Lower Ionosphere, J. Geophys. Res., 77, 1923-1933, doi:10.1029/JA077i010p01923, 1972.

Subcommittee for the NSF Upper Atmosphere Facilities: Upper Atmosphere Facilities: Integrating Management, Operations, and Science, Cornell University, Ithica NY, 66 pp., 2008.

Sulzer, M. P., Mathews, J. D., and Tomko, A. A.: A UHF cross-modulation D region heating experiment with aeronomic implications, Radio Sci., 17, 435-443, 
doi:10.1029/RS017i002p00435, 1982.

Swartz, W. E., Kelley, M. C., Makela, J. J., Collins, S. C., Kudeki, E., Franke, S., Urbina, J., Aponte, N., Sulzer, M. P., and Gonzalez, S. A.: Coherent and incoherent scatter radar observations during intense mid-latitude spread F, Geophys. Res. Lett., 27, 2829-2832, 2000a.

Swartz, W. E., Makela, J. J., and Kelley, M. C.: First observations of coherent scatter from the mid-latitude F-region in the Caribbean, Geophys. Res. Lett., 27, 935-938, 2000b.

Tellegen, B. D. H.: Interaction between Radio-Waves?, Nature, 131, 840, doi:10.1038/131840a0, 1933.

Tepley, C. A.: Current developments at Arecibo for research in the atmospheric sciences at low latitudes, J. Atmos. Sol.-Terr. Phys., 59, 1679-1686, doi:10.1016/S1364-6826(96)00167-8, 1997.

Thidé, B., Hedberg, Å., Fejer, J. A., and Sulzer, M. P.: First observations of stimulated electromagnetic emission at Arecibo, Geophys. Res. Lett., 16, 369-372, doi:10.1029/GL016i005p00369, 1989.

Thome, G. D.: Incoherent scatter observations of traveling ionospheric disturbances, J. Geophys. Res., 69, 4047-4049, doi:10.1029/JZ069i019p04047, 1964.

Thome, G. D.: A Study of Large-Scale Traveling Disturbances in the Ionosphere Using the Arecibo UHF Radar, Ph.D. thesis, Cornell, 1966.

Thompson, T. W.: Map of lunar radar reflectivity at 7.5-m wavelength, Icarus, 13, 363-370, doi:10.1016/0019-1035(70)900862, 1970 .
Trost, T. F.: Thomson scatter study of ionospheric scintillations, Case Western Reserve University, 1969.

Utlaut, W. F.: An ionospheric modification experiment using very high power, high frequency transmission, J. Geophys. Res., 75, 6402-6405, doi:10.1029/JA075i031p06402, 1970.

Watkins, C. D.: Notes on the use of the $40 \mathrm{MHz}$ radar for ionospheric incoherent scatter experiments at Arecibo, Center for Radiophysics and Space Research, CRSR-271, Cornell University, 1967.

Woodman, R. F.: High-altitude resolution stratospheric measurements with the Arecibo 2380-MHz radar, Radio Sci., 15, 423430, doi:10.1029/RS015i002p00417, 1980a.

Woodman, R. F.: High-altitude resolution stratospheric measurements with the Arecibo 430-MHz radar, Radio Sci., 15, 417-422, doi:10.1029/RS015i002p00417, 1980b.

Woodman, R. F. and Guillen, A.: Radar observations of winds and turbulence in the stratosphere and mesosphere, J. Atmos. Sci., 31, 493-506, doi:10.1175/15200469(1974)031<0493:ROOWAT>2.0.CO;2, 1974.

Zhou, Q., Tepley, C. A., and Sulzer, M. P.: Meteor observations by the Arecibo $430 \mathrm{MHz}$ incoherent scatter radar I. Detection, statistics, and interpretation, J. Atmos. Terr. Phys., 57, 412-431, 1995.

Zhou, Q.-H., Perillat, P., Cho, J. Y. N., and Mathews, J. D.: Simultaneous meteor echo observations by large aperture VHF and UHF radars, Radio Sci., 33, 1641-1654, 1998. 